\title{
Diagnosis of Ventilator Associated Pneumonia: Is There a Simple Solution?
}

\author{
RAKESH LODHA AND SK KABRA \\ Department of Pediatrics, All India Institute of Medical Sciences, Ansari Nagar, New Delhi.rakesh_lodha@hotmail.com
}

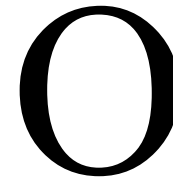
ver the last fifty years, mechanical ventilation has undoubtedly represented an advance in the treatment of respiratory insufficiency. However, nosocomial pneumonia has emerged as a leading complication of ventilation - increasing morbidity, mortality and health care costs. Ventilator associated pneumonia (VAP) has been found to have varying rates in different studies based on the population studied and the type of diagnostic techniques used. While the incidence of VAP in children, according to the data from hospitals enrolled in the National Care and Safety Network, has been found to be as low as 2.3 per 1000 ventilator days in pediatric medical ICUs in the United States, VAP continues to be the second most common health care associated infection even in developed countries [1]. Two studies from India have shown contrastingly high VAP rates of $32.5 \%$ and $20 \%$ in children ventilated in Pediatric Intensive Care Units (PICU) [2,3]. In a recently published study from a tertiary care center in north india, the incidence of VAP was reported as 17.5/100 patients [4].

The diagnosis of VAP in children is challenging. While early diagnosis is essential to improve the outcomes, there is also a concern about accuracy of diagnosis to prevent overuse of antibiotics. The gold standard for diagnosis is a combination of histopathology and culture of lung tissue. However, this is not feasible in most children. In such a scenario, one has to rely upon various combinations of clinical, radiologic imaging and microbiologic criteria; the CDC criteria for diagnosis of VAP include all these.
Clinical findings - fever, purulent secretions, tachypnea, appearance of bronchial breath sounds, crepitations, and worsening hypoxemia - have a poor sensitivity and specificity for diagnosis of VAP [5]. These criteria are used only in combination with imaging and microbiologic criteria. Appearance of new infiltrates, air bronchograms, other findings suggestive of pneumonia, or progression of infiltrates may suggest a diagnosis of VAP. However, the specificity of such findings is poor; patchy atelectasis may give rise to similar findings [6]. Microbiologic investigations have to be performed for the confirmation of diagnosis of VAP in a child who is suspected to have clinical and radiologic features suggestive of VAP. A variety of sampling techniques like bronchoalveolar lavage (BAL), mini-BAL, and non-bronchoscopic BAL, are feasible for the collection of samples for microbiologic diagnosis. The commonly used sample of tracheal aspirate has poor specificity.

To facilitate the diagnosis of VAP, a combination of various parameters may be useful. The Clinical Pulmonary Infection Score (CPIS) was developed by Pugin et al., [7] using a combination of six clinical, radiologic, and microbiologic criteria: temperature, white cell count, sputum, oxygenation, culture of tracheal aspirates, and radiology; each parameter was scored from 0 to 2 and a total score of $>6$ points suggested a diagnosis of VAP. When compared to histopathology, 2 studies in adults reported the sensitivity of CPIS score as $72 \%$ and $77 \%$, while the specificity was $85 \%$ and $42 \%$ respectively $[8,9]$. There are limited reports on the use of CPIS in children. A recent study evaluating the closed- 
system suctioning reported on the utility of CPIS; the difference in diagnostic rate using CPIS compared to CDC criteria was not significant [10]. Similarly, another study reported good performance of CPIS in comparison to BAL fluid culture [11].

The disadvantage of CPIS is the dependence on tracheal aspirate gram stain and/or culture results which may be available only after a waiting period of 24 to 48 hours; a 'simplified CPIS' may overcome this [12]. This simplified score was used by the authors to identify early in the hospital course of ventilator-associated pneumonia (VAP) which patients are responding to therapy.

In this issue of the journal, Sachdev et al.,[13] report the validation of 'simplified CPIS' for diagnosis of VAP in 30 children. Children with a 'simplified CPIS' of $>6$ were suspected to have VAP and underwent bronchoscopy and BAL. The diagnosis of VAP in these children was confirmed based on a quantitative culture. The authors report a sensitivity of $80 \%$, specificity $80 \%$, PPV $86.9 \%$, NPV $70.5 \%$ and accuracy $80 \%$ at a cut-off score of 8 . The authors provide useful evidence for the use of a simple score to assist in the diagnosis of VAP. However, the use of cut-off score of $>6$ is based on CPIS and not 'simplified CPIS'. It will be desirable to have further studies enrolling larger numbers to confirm utility of 'simplified CPIS'.

There has also been an interest in various biomarkers to assist in the diagnosis of VAP to optimize the therapy. Of these, serum procalcitonin has been in the forefront, however, the results have been varied [14]. Serial estimations of procalcitonin may assist in reducing the duration of antibiotic therapy for VAP [14]. The search for optimal biomarkers is on.

Competing interests: None stated

Funding: None.

\section{REFERENCES}

1. Edwards JR, Peterson KD, Andrus ML, Dudeck MA, Pollack DA, Horan TC. National Healthcare Safety Network Report: data summary from 2006 through 2007. Am J Infect Control. 2008;36:609-26.
2. Patra PK, Jayashree M, Singhi S, Ray, Saxena AK. Nosocomial pneumonia in a pediatric intensive care unit. Indian Pediatr. 2007;44:511-8.

3. Sharma H, Singh D, Pooni P, Mohan U. A study profile of ventilator associated pneumonia in children in Punjab. J Trop Pediatr. 2009;55:393-5.

4. Gupta A, Kapil A, Lodha R, Sood S, Dhawan B, Das BK, et al. Burden of healthcare-associated infections in a paediatric intensive care unit of a developing country: a single centre experience using active surveillance. J Hosp Infect. 2011;78:323-6.

5. Tejerina E, Esteban A, Fernandez-Segoviano P, FrutosVivar F, Aramburu J, Ballesteros D, et al. Accuracy of clinical definitions of ventilator-associated pneumonia: Comparison with autopsy findings. J Crit Care. 2010;25:62-8.

6. Wright ML, Romano MJ. Ventilator-associated pneumonia in children. Semin Pediatr Infect Dis. 2006;17:58-64.

7. Pugin J, Auckenthaler R, Mili N, Janssens JP, Lew PD, Suter PM. Diagnosis of ventilator-associated pneumonia by bacteriologic analysis of bronchoscopic and nonbronchoscopic 'blind' bronchoalveolar lavage fluid. Am Rev Respir Dis. 1991;143:1121-9.

8. Fàbregas N, Ewig S, Torres A, El-Ebiary M, Ramirez J, de La Bellacasa JP, et al. Clinical diagnosis of ventilator associated pneumonia revisited: Comparative validation using immediate post-mortem lung biopsies. Thorax. 1999;54:867-73.

9. Papazian L, Thomas P, Garbe L, Guignon I, Thirion X, Charrel J, et al. Bronchoscopic or blind sampling techniques for the diagnosis of ventilator-associated pneumonia. Am J Respir Crit Care Med. 1995;152: 1982-91.

10. Morrow BM, Mowzer R, Pitcher R, Argent AC. Investigation into the effect of closed-system suctioning on the frequency of pediatric ventilator-associated pneumonia in a developing country. Pediatr Crit Care Med. 2011 Jan 28. [Epub ahead of print].

11. Said AS, Abd-Elaziz MM, Farid MM, Abd-Elfattah MA, Abdel-Monim MT, Doctor A. Evolution of surfactant protein-D levels in children with ventilator-associated pneumonia. Pediatr Pulmonol. 2011 Sep 7. [Epub ahead of print].

12. Luna CM, Blanzaco D, Niedermn MS, et al. Resolution of ventilator associated pneumonia: Prospective evaluation of the clinical pulmonary score as an early clinical predictor of outcome. Crit Care Med. 2003;31:676-82.

13. Sachdev A, Chugh A, Sethi M, Gupta N, Wattal C, Menon G. Clinical Pulmonary Infection Score to diagnose ventilator associated pneumonia in children. Indian Pediatr. 2011;48:949-54.

14. Luyt CE, Combes A, Trouillet JL, Chastre J. Value of the serum procalcitonin level to guide antimicrobial therapy for patients with ventilator-associated pneumonia. Semin Respir Crit Care Med. 2011;32:181-7. 